\title{
Empowering Physics Students' Performance in a Group Discussion Through two Types of Peer Assessment
}

\section{Rif'ati Dina Handayani}

Corresponding author, Physics Education Department, University of Jember, Indonesia, rifatidina@gmail.com

\section{Marlina Ummas Genisa}

Biology Education Department, Muhammadiyah University of Palembang, Indonesia

\section{Triyanto}

Civic Education Department, Sebelas Maret University, Indonesia

$$
\text { | }
$$

Group discussions are often used to improve students' participation in the learning process. Unfortunately, the most frequent problem is teacher difficulty assessing the contribution of each group member. This research aimed to explore student performance in group discussion through two types of peer assessment. Data were collected through interviews, observation, and peer assessment. There were two types of peer assessment: internal and external. This research indicated that both types of peer assessment enhanced students' performance in group discussions and involved interpersonal skills, teamwork, and problem-solving. Both types of peer assessment in this research eliminated the students' laziness, reduced intimidation by the active students, gave all members equal responsibility, and provided feedback to help them develop their participation in group discussion. The students became more aware of the weaknesses and strengths of their performance. This study is expected to provide an additional method in the learning process for teachers to assess and enhance student performance.

Keywords: student performance, group discussion, internal peer assessment, external peer assessment, interpersonal skills, teamwork, problem-solving

\section{INTRODUCTION}

Physics is a knowledge-rich subject, and the rules are encapsulated in precise mathematical forms. Many students in physics lectures must study to unpack the compact mathematical laws of physics and use them in various situations to describe and predict physical phenomena (Mason \& Singh, 2016b). In short, learners must study to interpret and make sense of abstract physical principles and present a conscious effort to

Citation: Handayani, R. D., Genisa, M. U., \& Triyanto (2019). Empowering Physics Students' Performance in a Group Discussion Through two Types of Peer Assessment. International Journal of Instruction, 12(1), 655-668. https://doi.org/10.29333/iji.2019.12142a 
establish a comprehensive knowledge structure. Mastering physics amounts to not only developing a robust knowledge structure of physics concepts but also developing a student's performance (Mason \& Singh, 2016a; Wilcox \& Lewandowski, 2016).

Active learning has become an essential pedagogical focus. Active learning is a process activity that engages students in the learning process (Prince, 2004). In short, active learning requires students to do meaningful learning activities and think about what they are doing. Students learn when they are actively involved in the learning process. Active learning provides definite independence, individual accountability, and social skills to improve students' understanding and personal development (Silberman \& Biech, 2015). One of the methods that encourage students to be more active in learning is discussion. Discussion makes students work together in solving problems through information retrieval and exchanging ideas. Discussion can be between teacher and students and among students (Omatseye, 2007). Usually, the discussion's goal is to achieve a consensus among the group's members. Group composition is based on individual knowledge and interests, spurring better discussions or interactions during learning. Discussion can perform a corrective function when members individually have incomplete and biased information but collectively can piece together unbiased information from the alternatives (Stasser \& Titus, 1985). Group discussion has its origins in a range of active learning strategies aimed to stimulate students' interest in what they are studying by providing a significant degree of autonomy over the learning activity (Bennett, Hogarth, Lubben, Campbell, \& Robinson, 2010). Hamann, Pollock, and Wilson (2012) also explained that discussion is a useful method to facilitate student learning. Discussions can be structured and organized in many different ways to accommodate varying environments.

The implementation of discussions sometimes does not correspond to the purpose of learning. The benefits of discussion are abundant, but not all students are likely to participate. This disparity has limited the value of discussion for some students. Some students feel unable to say what they mean and are afraid of being wrong if they contribute, while other students may be intimidated by the dominant participant. Some discussion groups are dominated by students who are more intelligent and active. So, it's hard to determine the extent of each group member's understanding and mastery of the assigned material. In social situations, some individuals are more anxious than others (Watson \& Friend, 1969). The student team member does not contribute his/her full potential (Joyce, 2010). Some students cannot engage in group discussions, and the majority of students tend to be passive and remain silent in group discussions because of diminished ability to dialogue and lack of confidence to share their ideas. Students feel shy to express their opinions or complete the assigned task and tend to assign responsibility to the active students. Some active students also have disproportionate influence, which makes group discussions less comfortable. In short, active students in the group take over and work independently, discouraging the participation of other team members. In various learning teams, low-achieving students may make few contributions to the group's effort, which can be presented by the high achievers. Based on this explanation, one solution is applying peer assessment, which involves students evaluating their fellow group members. Peer assessment incorporates many features of 
collaborative learning (Prins, Sluijsmans, Kirschner, \& Strijbos, 2010). Involving the student is expected to spur self-awareness to explore and discuss the subject matter that will enhance the academic achievement.

\section{Theoretical Framework}

\section{Group Discussion}

Discussions are situations in which teachers and students or students and other students share their ideas and change their opinions. Questions to stimulate discussion are usually at a higher cognitive level (Arends, 2009). The forum permits students to express their views and clarify their ideas (Chiappetta \& Koballa, 2009). It is a good strategy for promoting student involvement in the classroom. Teachers use discussions to achieve at least three significant instructional objectives: first, to improve students' thinking and help them construct their understanding of the subject matter content; second, to promote students' involvement and engagement; third, to help students to learn valuable communication skills and develop more effective thinking processes (Arends, 2009). According to Dallimore, Hertenstein, and Platt (2004), the benefits of discussion include helping students to develop their critical thinking, self-awareness, appreciation for diverse perspectives, and ability to take action. This view is consistent with both sociocognitive and sociocultural perspectives of learning. From a socio-cognitive perspective, learning is a cognitive process embedded in social contexts, so both social and cognitive factors influence the outcomes of learning processes (Wilkinson \& Fung, 2002). From a sociocultural perspective, learning is constructed during interaction and activity with others, so there is interdependence of social and individual processes in the coconstruction of knowledge (Wilkinson \& Fung, 2002). However, for the discussion to be productive and focused on the intended learning outcomes of the lesson, its purpose must be made clear (Lau, Kwong, Chong, \& Wong, 2013). The students must listen carefully, and responses must focus on the relevant content being discussed (Tesfaye \& Berhanu, 2015).

\section{Peer Assessment}

Assessment is an integral part of the teaching and learning process. Peer assessment has been used successfully in a higher education institution, with significant benefits reported regarding student learning (Ballantyne, Hughes, \& Mylonas, 2002). Peer assessment is defined as a set of activities through which individuals consider the amount, level, value, worth, quality, or success of the products or outcomes of learning and make judgments about the work of others (Reinholz, 2016). Students' behavior and attitude are profoundly influenced by the assessment system. Peer assessment provides students with opportunities to reveal their understanding, assemble previous knowledge, generate inferences, assimilate ideas, repair misunderstandings, and describe and converse about their understanding (Roscoe \& Chi, 2007). According to Spiller (2012), all assessments comprise two main elements: making decisions about the standards of interpersonal skill expected and then making judgments about the quality of the participation. Students should ideally be involved in both of these aspects. The students learn more when the assessment procedure includes feedback on the products and 
processes (van den Berg, Admiraal, \& Pilot, 2006). Peer assessment requires students to clarify and correct each other's work and to provide either feedback or grades (or both) to their peers based on the criteria of excellence in that performance or event, which students may have been involved in determining (Topping, Smith, Swanson, \& Elliot, 2000). This strategy is expected to explore the fundamentals of the assessment process, provide descriptive feedback, and maximize the students' interpersonal skills. Studies of the assessment must be carried out even further to consider the appropriate types of assessment in group discussions and learning in the classroom.

\section{METHOD}

\section{Research Question}

The aim of this research was to explore student performance in group discussion through two types of peer assessment, internal peer assessment within members in the group and external peer assessment among groups. The research question: how do two types of peer assessment strengthen physics student performance in a group discussion?

\section{Setting and Sample}

The setting chosen for this research was the undergraduate computational physics course in the fourth quarter of 2016 at the University of Jember. The participants consisted of 96 physics students. There were 67 females (69.79\%) and 29 males $(30.21 \%)$ in their 20 s and their second year of physics degrees. Computational physics is the study and implementation of numerical analysis to solve problems in physics for which a theory already exists. In the learning process, computational physics requires a lot of discussions and projects to be constructed and finished together or by groups. The student participants were divided into 24 groups of four students. This small group size is more appropriate and accessible to evaluate.

\section{Instrument}

Student performance was measured using a narrative peer assessment rubric. Narrative is a conventional form transmitted culturally and constrained by each individual's level of mastery, colleagues, and mentors. Narrative assessment is an approach to assessing and describing a student's learning that allows a far more precise depiction of that learning than is possible through more traditional criterion-referenced assessment (Bourke \& Mentis, 2010). The rubric for internal assessment within the group included student participation, contribution to completing the project, teamwork, and attitude. The rubric for external assessment was based on the project outcome and presentation and used simple questions geared to elicit feedback about positive and negative aspects from the students' perspectives. Content validity was addressed by consulting among various professors specializing in educational foundations and other educational disciplines. This consultation resulted in a series of substantive changes to both the assessment rubrics. Reliability was checked using SPSS, and the Cronbach's alpha was 0.81 . 


\section{Peer Assessment Procedure}

In this research, the students were asked to participate in collaborative learning and form their groups of four students. Students were given a project to select one of the physics concepts and make a visual simulation; then they were to present their group's project results in class. The lecturer's role in the course was to serve primarily as a facilitator of group learning, monitoring progress.

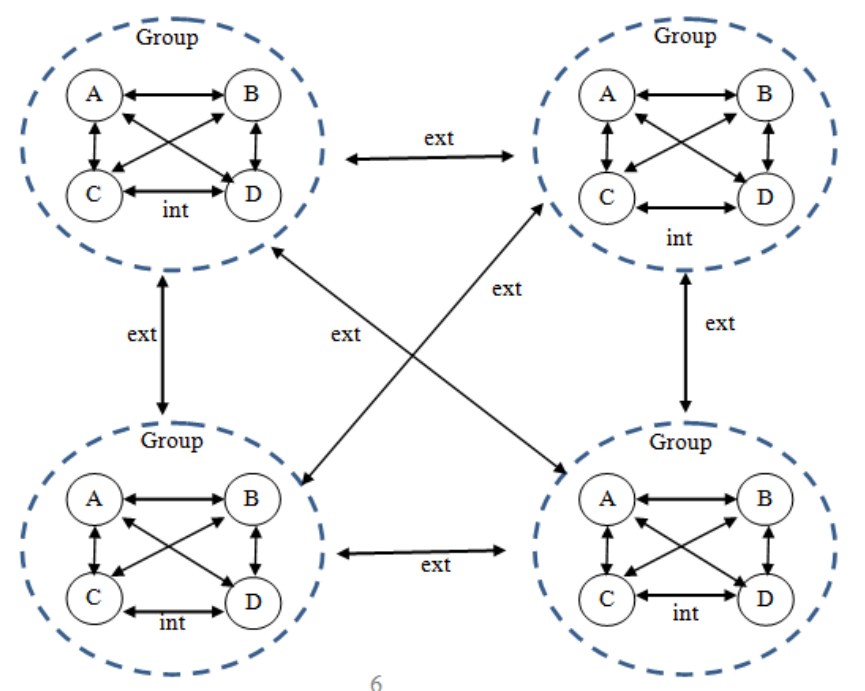

Figure 1

Peer assessment illustration, internal and external peer assessment

There are two types of peer assessment in this study: (1) the evaluation carried out by members of a group (internal group) and (2) the evaluation conducted by other groups (external group), as illustrated in figure 1. Peer assessment within the group was held to enhance student participation in the completion of the project. Each member of the team was to assess each other in a narrative form about their involvement, including their contribution to the group, teamwork, and attitude. This assessment's purpose was to eliminate domination by excellent students and reduce dependency on others. Furthermore, this evaluation was also meant to allow the teacher to control student performance outside class hours. Meanwhile, peer assessment was conducted by external groups regarding the project outcome and presentation. Both peer assessments were anonymous, identified, and asynchronous.

\section{Data Analysis}

The data were collected by interviews, observation, and both student peer assessments' results. The participants were interviewed individually before and after the assessment. In this study, a semi-structured interview format was used as a qualitative research method to achieve some in-depth information about the students' views and 
performance in the learning process. Semi-structured interviews offer a subject and questions to the interviewee but are carefully designed to elicit the interviewee's ideas and opinions on the topic of interest, as opposed to leading the respondent toward preconceived choices. The observation started with the first group discussion and was completed at the last group discussion about 4 months later, which means that all the student activities were captured. This was the main component of this research, and all the data helped the researchers interpret the research purposes.

Qualitative data were analyzed by the researchers through six stages: organizing data, exploring and sorting data, encoding to construct themes, descriptive analysis, sustainability analysis and invention interpretation, and validation. Encoding meant reading student peer assessment notes and repeatedly watching each video recording until themes began to emerge - certain activities, ideas, etc. Validation was executed by the triangulation method. Triangulation, according to Johnson and Christensen (2013, p. 299 ), is used to make studies and research process more systematic; it mutually crosschecks information so that conclusions taken through various procedures or sources are trustworthy.

\section{FINDINGS}

Both types of peer assessment in this research were focused on physics student learning performance during group discussion. This assessment might take the form of a personal comment on how the group worked, how the individual felt another member of the group contributed, and what the good and bad points of the experience of working together and presenting were. It could also take the form of a short written piece of feedback or a reflection. The results of peer analysis within and between groups are presented in tables 1 and 2 .

Table 1

$\underline{\text { Result of peer analysis within group of student performance (internal peer assessment) }}$

\begin{tabular}{|c|c|c|}
\hline Indicator & Visible Performance & Student Performance \\
\hline $\begin{array}{l}\text { Contribution to } \\
\text { the Group }\end{array}$ & $\begin{array}{l}\text { - Giving ideas and opinions } \\
\text { - Searching and reading various literature } \\
\text { - Providing facilities }\end{array}$ & $\begin{array}{l}\text { - Interpersonal skills } \\
\text { - Problem solving } \\
\text { - Problem solving }\end{array}$ \\
\hline Group Building & $\begin{array}{l}\text { - Completing the task } \\
\text { - Making a decision } \\
\text { - Collaboration }\end{array}$ & $\begin{array}{l}\text { - Team working } \\
\text { - Problem solving } \\
\text { - Team working } \\
\end{array}$ \\
\hline $\begin{array}{l}\text { Member's } \\
\text { Attitude }\end{array}$ & $\begin{array}{l}\text { - Respect } \\
\text { - Responsibility } \\
\text { - Listening to another opinion } \\
\text { - Paying close attention } \\
\end{array}$ & $\begin{array}{l}\text { - Interpersonal skills } \\
\text { - Interpersonal skills } \\
\text { - Interpersonal skills } \\
\text { - Interpersonal skills } \\
\end{array}$ \\
\hline
\end{tabular}


Table 2

Results of peer analysis between groups on student performance (external peer assessment)

\begin{tabular}{lll}
\hline Indicator & Visible Performance & Student Performance \\
\hline \multirow{2}{*}{ Project } & - The project simulation was interesting. & - Interpersonal skills \\
Outcome & - The project simulation was clear and easy to & - Team working \\
& understand. & \\
\hline \multirow{2}{*}{ Project } & - The project simulation increased knowledge. & - Problem solving \\
Presentation & - Dealing with and answering the question & - Interpersonal skills \\
& - Time management & - Problem solving \\
& - Readiness to present & - Problem solving \\
& - Ottitude during presentation & - Team working \\
\end{tabular}

\section{DISCUSSION}

\section{Interpersonal Skills}

Interpersonal skills commonly developed in a physics class are those needed for a group to complete its task, be it an activity, experiment or project. Interpersonal skills are an individual's skills to perform adequate communication. Students' interpersonal skills related to effective team participation, helping a team to achieve the learning purposes and to move the student progressively toward stronger performance. This requires effective communication, empathy, listening to others, showing respect for people, providing arguments to support your proposed or actual actions, critical self-evaluation, and paying close attention (Skinner, Hyde, McPherson, \& Simpson, 2016). Such skills, together with thinking skills are among self-learning and lifelong learning skills applicable to many areas of life.

The implementation of peer assessment makes students more active in learning; they listen and pay close attention to the group discussion and the project presentation. They listen to opinions from other members of the group, try to understand, and then express their views in the discussion. The students listened to their friends and commented on each other's ideas, thereby increasing their self-confidence. One participant said,

I try to argue; it's tough because I'm a quiet person. I prefer to listen to the opinions of my friends. (Interviewed April 12, 2016)

Implementation of peer assessment is expected to be through assessing the contributions of peers in expressing ideas and opinions. Topping et al. (2000) was convinced that peer assessment improves students' learning by developing their understanding, encouraging them to reflect on their approach, and enhancing their self-confidence as well as the quality of their continuous work. Peer assessments within a group made the students more active and communicative in the preparation for and completion of the simulation project. They were responsible for the group task, engaged in every discussion, and appreciated the different ideas among members of the group. 
Through the presentation of the project, I got a lot of interesting knowledge and could provide feedback to other groups through external peer assessment. (Interviewed April 22, 2016)

Throughout group discussion, the students can share their ideas through collaboration and communicate what is in their minds. They reported that peer assessment in group discussion greatly appreciated student opinion and interaction among students. The students considered that a few management guidelines and a chance to communicate and present the seminar early on in the course would be useful. Peer assessment brings more real and reliable results than teacher evaluation (Mehrdad, Bigdeli, \& Ebrahimi, 2012).

\section{Team Working}

Teamwork has many potential benefits over individual working, including offering a broader range of perspectives and encouraging responsibility (Eva, 2002). By working in groups, students can develop team working skills differently and exercise a range of skills, including both written and oral communication. Teams have a more considerable well of resources to tap and more information accessible because of the variety of backgrounds and experiences. The assessment by members of one group makes the students more reliable and participative in the group work to complete their project. Students in groups shared tasks to complete projects.

The group assessment makes me more emotionally bonded that I am part of a group. (Interviewed May 11, 2016)

Physics students work in teams on a mutual project, prepare a joint report and shared presentation. They were responsible for the group work preparing the presentation of the results of the project, were active in every discussion meeting, and appreciated the different ideas when discussing. The students could help each other to make sense of the gaps in their learning and understanding to get a more sophisticated grasp of the learning process. Students engaged in commentary on the work of others can heighten their capacity for judgment and make intellectual choices, students receiving feedback from their peers get a more extensive range of ideas about their work to promote development and improvement, and peer evaluation helps teachers and students to enhance the students' status in the learning process.

Use of peer evaluation was significant to enhance assertiveness toward teamwork, such as by allowing students to feel that they were more in control of the results of their efforts and to respect other views. Peer assessment allowed students to have a sense of control over their achievement and provided a legitimate opportunity to express dissatisfaction with team members. Through peer assessment, collaboration between members arises, and responsibility becomes a solid basis for completing the task. Group members provide each other support to try out and articulate a new idea and share ideas and definitions of the task, the subject, the materials, and the method of presentation. Peer assessment in group discussion trains them to help each other and to respect the opinions of others. One student stated, 
I feel helped by this teamwork because I have difficulty in communicating, but I have many ideas. Through this discussion, my problem is solved, and our team can complement each other. (Interviewed May 3, 2016)

Some students concentrated on deepening their understanding of group relationships in the workstation, while others aimed to develop their capacities to engage in effective professional dialogues. Thus, peer assessments appear to be particularly beneficial in the context of group working (Falchikov, 1991). Students working in small groups tend to study more about what is taught and retain it longer than when the same material is presented in other instructional forms.

\section{Problem Solving}

Physics is a part of science that consists of theory, and the laws of physics are usually packed in the form of exact mathematical equations. Students in advanced physics mostly solve the laws of physics mathematically and apply them in different situations using simulation and experiment to be able to explain and predict phenomena (Mason \& Singh, 2016b; Yap \& Wong, 2007). In other words, to understand a physics concept, students must learn how to interpret and use logic for abstract physics principles and strive to create a coherent structure of knowledge. The mathematical structure in physics is used as a frame of reference or framework for building a robust and well-organized understanding of a subject in which the concepts and structure of knowledge are interrelated. Complex physics concepts can be learned together through a study group or discussion that helps each to develop his ability to solve a problem.

Problem-solving is an intellectually demanding activity of central importance in any science. It is a challenging task to design instructional methods for proper scientific problem-solving skills. Giving a project through group discussion can impact how well students learn physics and how successful they are in solving physics problems. Approaches to problem-solving often result from strategies that engage students actively in the learning process, e.g., peer instruction and collaborative group problem-solving. The ability to understand content knowledge and use it to solve scientific problems is fundamental for a meaningful understanding of science (Brandstädter, Harms, \& Großschedl, 2012). Groups stimulate creativity. Regarding problem-solving, the adage can be applied that "two heads are better than one."

The implementation of peer assessment within the group gives the students the responsibility to complete the project. They use all their intellectual abilities to accomplish the project as well as possible. The students were searching and reading the various literature through textbooks, the internet, and journals to find solutions for their additional knowledge. One student stated,

Peer assessment in the group pushes my brain to think harder-such a nerd. (Interviewed April 19, 2016)

Reading is a way to promote many aspects of science by forming ideas and grasping meaning (Chiappetta \& Koballa, 2009). Peer assessment encourages students to improve their critical thinking skill and to reflect on their behavior and performance. In short, peer assessment increases their awareness of the quality of their work and group work. 
Critique and feedback from peers are invaluable for the students to enhance their performance to solve a problem. Venables and Summit (2003) and Anderson et al. (2000) posited that the level of student cognition about content knowledge improves through peer feedback. Peer assessment improves student learning by enabling the students to view and critique a range of ideas and abilities, thus encouraging them to learn from the mistakes and exemplary performance of their peers (Hanrahan \& Isaac, 2001). Research suggests that students who are engaged in group problem solving are more committed to the solution and are better satisfied with their performance in the group than those who are not involved.

\section{Student Response}

The majority of participants had positive views on the group discussion. They thought that group discussion was an excellent idea and the learning process became enjoyable. They could express their thoughts and feelings. The creation of study support encouraged their personal development. When assessing other groups, they compared the presentation of each group, including their own group's project. In short, the students learned about self-evaluation directly. This is essential for avoiding negative criticism. A student stated,

I got much benefit from this assessment, such as eliminating my feeling lazy, reduces intimidation from the active student, and all group members have equal responsibility.. (Interviewed May 23, 2016)

Having explicit and unambiguous criteria helps this process, but it is still a challenge for students to take their work and make judgments about it. Peers helped students to improve their ability to judge. A few students recognized ambivalence about group discussion. One said that

It was good for correcting and reporting it to others but hard to communicate how to give constructive feedback without hurting and intervening. (Interviewed May 13, 2016)

The students valued peer assessment as a meaningful activity and the benefit from providing feedback (Xiao \& Lucking, 2008). Contrary responses focused on the fact that a written evaluation of the other group members was uneasy because they were a team. This opinion aligns with Pitt and Norton (2016), who found that some students fail to take note of their feedback or sometimes do not collect assignments that have been marked. But we believe that university students have the ability to assess their peers' products and separate their emotional condition. Kirby and Downs (2007) argued that one of the characteristics of effective learners is that they have a realistic sense of their strengths and weaknesses, and they can use self-knowledge to direct their studying in productive directions.

Through peer assessment, I learned to evaluate myself before I assess my friend. (Interviewed May 11, 2016)

Assessment conducted by the peer group can provide more objective evaluation because peers know students' contributions better than teachers, but the results of audience assessment need to be correlated back to the teacher's assessment. Students appeared 
responsive to the idea of being included in the process and giving positive feedback enthusiastically. Peer assessment is essential for the student as it provides students with valuable skills for professional contexts and trains them for future learning (Alias, Masek, \& Salleh, 2015). The students appreciated the concept and implementation of peer assessment, and it was appropriate for the course. Peers' involvement in assessment processes should be more than just grading peers' work and comparing the scores with those of the tutor.

\section{CONCLUSION}

This research indicated that two types of peer assessment enhanced student performance in group discussions: interpersonal skills, teamwork, and problem-solving. Peer assessment eliminated the students' feeling lazy, reduced intimidation from the active students, gave all members equal responsibility, and helped them to develop their participation through feedback. This study suggests that deeper examination is needed of how to critique without hurting and discriminating. In addition, the development of digital or online peer assessment needs to be accomplished for more interactive and efficient learning. This research is expected to provide review of critical peer assessment in the learning process.

\section{REFERENCES}

Alias, M., Masek, A., \& Salleh, H. H. M. (2015). Self, peer and teacher assessments in problem based learning: are they in agreements? Procedia - Social and Behavioral Sciences, 204(November 2014), 309-317. https://doi.org/10.1016/j.sbspro.2015.08.157

Anderson, L. W., Krathwohl, D. R., Airasian, P. W., Cruikshank, K. A., Mayer, R. E., Pintrich, P. R., ... Wittrock, M. C. (2000). A Taxonomy for learning, teaching, and assessing: A revision of bloom's taxonomy of educational objectives, Abridged Edition (1 edition). New York: Pearson.

Arends, R. I. (2009). Learning to teach. (B. Mejia, Ed.) (Ninth Edit). New York: McGraw-Hill. https://doi.org/10.1017/CBO9781107415324.004

Ballantyne, R., Hughes, K., \& Mylonas, A. (2002). Developing Procedures for Implementing Peer Assessment in Large Classes Using an Action Research Process. Assessment \& Evaluation in Higher Education, 27(5), 427-441. https://doi.org/10.1080/0260293022000009302

Bennett, J., Hogarth, S., Lubben, F., Campbell, B., \& Robinson, A. (2010). Talking Science: The research evidence on the use of small group discussions in science teaching. International Journal of Science Education, 32(1), 69-95. https://doi.org/10.1080/09500690802713507

Bourke, R., \& Mentis, M. (2010). Research and Evaluation of Narrative Assessment and Curriculum Exemplars for Students with Special Education Needs. Special Education, (March).

Brandstädter, K., Harms, U., \& Großschedl, J. (2012). Assessing System Thinking 
Through Different Concept-Mapping Practices. International Journal of Science Education, 34(14), 2147-2170. https://doi.org/10.1080/09500693.2012.716549

Chiappetta, E. L., \& Koballa, T. R. (2009). Science Instruction in the Middle and Secondary Schools: Developing Fundamental Knowledge and Skills (7 edition). Boston, Mass: Pearson.

Dallimore, E. J., Hertenstein, J. H., \& Platt, M. B. (2004). Classroom participation and discussion effectiveness: student-generated strategies. Communication Education, 53(1), 37-41. https://doi.org/10.1080/0363452032000135805

Dochy, F., Segers, M., \& Sluijsmans, D. (1999). The use of self-, peer and coassessment in higher education: A review. Studies in Higher Education, 24(3), 331-350.

Eva, K. W. (2002). Teamwork during education: the whole is not always greater than the sum of the parts. Medical Education, 36(4), 314-316. https://doi.org/10.1046/j.1365-2923.2002.01204.x

Falchikov, N. (1991). Group process analysis: Self and peer assessment of working together. Standing Conference on Self and Peer Assessment, 8005(July), 15-27. https://doi.org/10.1080/0954730930300308

Hamann, K., Pollock, P. H., \& Wilson, B. M. (2012). Assessing Student Perceptions of the Benefits of Discussions in Small-Group, Large-Class, and Online Learning Contexts. College Teaching, 60(2), 65-75. https://doi.org/10.1080/87567555.2011.633407

Hanrahan, S. . ., \& Isaac, G. (2001). Assessing Self- and Peer-Assessment: The Students' Views. Higher Educatiion Reserach \& Development, 20(1), 53-68.

Johnson, R. B., \& Christensen, L. B. (2013). Educational research: Quantitative, qualitative, and mixed approaches (5 edition). Thousand Oaks, Calif: SAGE Publications, Inc.

Joyce, W. B. (2010). On the Free-Rider Problem in Cooperative Learning. ResearchGate, 74(5), 271-274. https://doi.org/10.1080/08832329909601696

Kirby, N. F., \& Downs, C. T. (2007). Self assessment and the disadvantaged student: Potential for encouraging self regulated learning? Assessment \& Evaluation in Higher Education, 32(4), 475-494. https://doi.org/10.1080/02602930600896464

Lau, P., Kwong, T., Chong, K., \& Wong, E. (2013). Developing students' teamwork skills in a cooperative learning project. International Journal for Lesson and Learning Studies, 3(1), 80-99. https://doi.org/10.1108/IJLLS-03-2013-0018

Mason, A. J., \& Singh, C. (2016a). Surveying college introductory physics students' attitudes and approaches to problem solving. European Journal of Physics, 37(5), 1-16. https://doi.org/10.1088/0143-0807/37/5/055704

Mason, A. J., \& Singh, C. (2016b). Using categorization of problems as an instructional tool to help introductory students learn physics. Physics Education, 51(2). https://doi.org/10.1088/0031-9120/51/2/025009 
Mehrdad, N., Bigdeli, S., \& Ebrahimi, H. (2012). A Comparative Study on Self, Peer and Teacher Evaluation to Evaluate Clinical Skills of Nursing Students. Procedia Social and Behavioral Sciences, 47, 1847-1852. https://doi.org/10.1016/j.sbspro.2012.06.911

Omatseye, B. O. J. (2007). The Discussion Teaching Method: an Interactive Strategy in Tertiary Learning. General Education Journal, 12(1), 87-95.

Pitt, E., \& Norton, L. (2016). 'Now that's the feedback I want!' Students' reactions to feedback on graded work and what they do with it. Assessment \& Evaluation in Higher Education:, 42(4), 499-516. https://doi.org/10.1080/02602938.2016.1142500

Prince, M. (2004). Does Active Learning Work? A Review of the Research. Journal Enger Education, 93(July), 223-231.

Prins, F. J., Sluijsmans, D. M. A., Kirschner, P. A., \& Strijbos, J.-W. (2010). Formative peer assessment in a CSCL environment: a case study. Assessment \& Evaluation in Higher Education, 30(4), 417-444. https://doi.org/10.1080/02602930500099219

Reinholz, D. (2016). The assessment cycle: a model for learning through peer assessment. Assessment \& Evaluation in Higher Education, 41(2), 301-315. https://doi.org/10.1080/02602938.2015.1008982

Roscoe, R. D., \& Chi, M. T. H. (2007). Understanding Tutor Learning: KnowledgeBuilding and Knowledge-Telling in Peer Tutors' Explanations and Questions. Review of Educational Research, 77(4), 534-574. https://doi.org/10.3102/0034654307309920

Silberman, M., \& Biech, E. (2015). Active Training A Handbook of Techniques, Designs, Case Examples, and Tips. Canada: John Wiley \& Sons, Inc.

Skinner, K. L., Hyde, S. J., McPherson, K. B. A., \& Simpson, M. D. (2016). Improving students' interpersonal skills through experiential small group learning. Journal of Learning Design, 9(1), 21-36. https://doi.org/10.5204/jld.v9i1.232

Spiller, D. (2012). Assessment Matters: Self-Assessment and Peer Assessment Assessment. In Teaching Development Unit (pp. 1-19).

Stasser, G., \& Titus, W. (1985). Pooling of unshared information in group decision making: Biased information sampling during discussion. Journal of Personality and Social Psychology, 48(6), 1467-1478. https://doi.org/10.1037/0022-3514.48.6.1467

Tesfaye, S., \& Berhanu, K. (2015). Improving Students' Participation in Active Learning Methods: Group Discussions, Presentations and Demonstrations: A Case of Madda Walabu University Second Year Tourism Management Students of 2014. Journal of Education and Practice, 6(22), 29-32.

Topping, K. J., Smith, E. F., Swanson, I., \& Elliot, A. (2000). Formative Peer Assessment of Academic Writing Between Postgraduate Students. Assessment \& Evaluation in Higher Education, 25(2), 149-169. https://doi.org/10.1080/713611428

van den Berg, I., Admiraal, W., \& Pilot, A. (2006). Peer assessment in university 
teaching: evaluating seven course designs. Assessment \& Evaluation in Higher Education, 31(1), 19-36. https://doi.org/10.1080/02602930500262346

Venables, A., \& Summit, R. (2003). Enhancing Scientific Essay writing using peer assessment. Innovations in Education and Teaching International, 40(3), 281-290.

Watson, D., \& Friend, R. (1969). Measurement of social-evaluative anxiety. Journal of Consulting and Clinical Psychology, 33(4), 448-457. https://doi.org/10.1037/h0027806

Wilcox, B. R., \& Lewandowski, H. J. (2016). Students' epistemologies about experimental physics: Validating the Colorado Learning Attitudes about Science Survey for experimental physics. Physical Review Physics Education Research, 12(1), 1-11. https://doi.org/10.1103/PhysRevPhysEducRes.12.010123

Wilkinson, I. A. G., \& Fung, I. Y. Y. (2002). Small-group composition and peer effects. International Journal of Educational Research, 37(5), 425-447. https://doi.org/10.1016/S0883-0355(03)00014-4

Xiao, Y., \& Lucking, R. (2008). The impact of two types of peer assessment on students' performance and satisfaction within a Wiki environment. The Internet and Higher Education, 11(3-4), 186-193. https://doi.org/10.1016/j.iheduc.2008.06.005

Yap, K. C., \& Wong, C. L. (2007). Assessing conceptual learning from quantitative problem solving of a plane mirror problem. Physics Education, 42(1), 50. https://doi.org/10.1088/0031-9120/42/1/005 